\title{
Observaciones sobre el teatro argentino contemporáneo
}

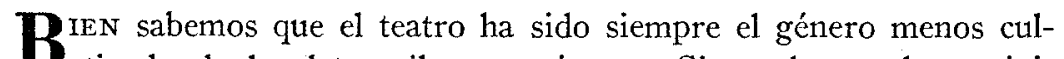
tivado de las letras iberoamericanas. Sin embargo, las actividades de la calle Corrientes, la Broadway porteña, durante las dos o tres temporadas anteriores han sido impresionantes. E1 interés en el teatro legítimo casi se puede comparar al que se tiene en el cine, sobre todo recientemente, a causa de las pocas cintas importadas de los Estados Unidos. Las entradas suelen agotarse pronto y muchas piezas se repiten no sólo uno y otro mes, sino también de una temporada a la siguiente.

No se puede negar que las comedias populares y musicales son las más aplaudidas. Siempre figura entre ellas el éxito de una compañia española de zarzuelas y operetas con un tenor-amante como Marcos Cubas o el guapo-villano-barítono, como Manuel Abad. ${ }^{1} \mathrm{La}$ farsa provoca igual entusiasmo, sobre todo, cuando la protagonista de una "aventura conyugal" tan popular como Esposa último modelo es la siempre versátil y brillante Paulina Singerman. ${ }^{2}$

En la producción escénica predominan obras españolas. El público sigue aplaudiendo año tras año el drama inmortal de José Zorrilla, Don Juan Tenorio, representado en recientes años por la compañía de don Joaquín Pibernat. Entre los demás dramaturgos del siglo pasado encontramos en el escenario porteño a Tamayo y Baus con su drama histórico-romántico Locura de amor. La actuación de María Guerrero en el papel de la reina doña Juana fué lamentable ${ }^{3}$ a pesar del nombre ilustre de la actriz, heredado de su abuela. 
Entre las compañías en Argentina se distinguió la de Mercedes Prendes con la representación de La risa, de los hermanos Alvarez Quintero. ${ }^{4} \mathrm{La}$ actriz española sobresalió en Añoranzas de Manuel Linares Rivas ${ }^{5}$ y en Adoración de Jacinto Benavente. ${ }^{6}$ Don Jacinto que todavía escribe ha dedicado una de sus últimas piezas, Divorcio de almas a Lola Membrives, distinguida actriz, nacida en Buenos Aires y educada en España. La señorita Membrives todavía tiene momentos felices en los que domina absolutamente su arte, como lo demostró en la obra de Jean Cocteau, El águila de dos cabezas. ${ }^{7}$ Los tres actos de la pieza del dramaturgo francés no son más que un monólogo trágico-humano-psicológico; sin embargo, Lola Membrives logró convencer en su actuación, revelando una plena madurez artística.

Ejerce más atracción en el público la producción de Alejandro Casona, célebre dramaturgo español que vive en Buenos Aires. Los árboles mueren de pie, que se estrenó en julio de 1949 en el Teatro Ateneo, ha sido uno de los grandes éxitos del teatro argentino reciente. Es una de las pocas piezas escritas en Argentina que ha sobrevivido dos temporadas del teatro porteño (y que goza de igual éxito en traducción portuguesa en Río de Janeiro.) La acción de la pieza se inicia en un instituto de apariencia curiosa. Parece ya manicomio, ya lugar fantástico en algún rincón de un mundo irreal (como en Huis-Clos de Jean-Paul Sartre.) Resulta que es un instituto que se sirve de mentiras beneficiosas para salvar a los hombres de los males. El director ayuda a un desesperado abuelo a forjar una mentira beneficiosa para evitar ủna desilusión a la abuelita. Esta, guiada por su corazón, adivinó la terrible verdad. El nieto tan querido era un miserable perverso. Sin embargo, ella guarda su secreto y rechaza al nieto, fingiendo no haberlo reconocido, y superando la tormenta de su alma con toda la fuerza vital de un árbol que "muere de pie". Amalia Sánchez Arino creó en la abuelita una figura inolvidable contribuyendo así, en sumo grado, al éxito de la obra.

Otra obra de Alejandro Casona estrenada en 1949 en el 'Ateneo fué La dama del alba. Apareció también en este "retablo poético". Amalia Sánchez Arino, actriz muy apreciada en Argentina y conocida además por las numerosas cintas nacionales en que trabaja. En el reparto encontramos asimismo a Luisa Vehil, cuyo gran 
talento se puso de manifiesto al representar a la Muerte que va y viene según las órdenes del destino. Juntó Luisa Vehil admirablemente el misticismo lírico con verdadera comprensión humana y con arte psicológico.

Las obras de Federico García Lorca no llegan al escenario oficial ni comercial; su público se limita a un grupo de entusiastas que entiende la sutileza de su poesía. La representación de Asi que pasen cinco años en julio de 1949 fué una verdadera apoteosis en la cual se reunió el entusiasmado público con los actores del Teatro Experimental "Los Pies Descalzos", así como con reconocidos hombres de letras como el poeta Rafael Alberti que dibujó el telón para ese acto presentado en homenaje al difunto autor. En Asi que pasen cinco años, "poema fantástico", el autor nos hacer ver la desesperación de la juventud, la tristeza de la vida, su semejanza con la muerte y la facilidad con que se encuentran el pasado con el futuro.

En cuanto a piezas norteamericanas, la obra de Arthur Miller Muerte de un viajante (Death of a Salesman) se mantuvo en escena durante dos temporadas (1949-1950) - cosa excepcional en la escena argentina. Los esfuerzos por captar el espíritu del original de Broadway no se coronaron con éxito a pesar del talento de Narciso Ibáñez Menta, el actor más distinguido del teatro argentino contemporáneo.

Cabe ahora pasar a la producción genuinamente nacional. Cada pieza de un autor argentino tiene que estrenarse en el Teatro Nacional Cervantes bajo la supervisión de la Comisión Nacional de Cultura, o debe representarse en un teatro experimental antes de llegar al teatro comercial.

Entre los jóvenes dramaturgos, Carlos Gorostiza ocupa un lugar destacado. Su comedia El puente tuvo el raro privilegio de ser representada durante las dos temporadas de 1949 y 1950 simultáneamente en un teatro experimental y en el Teatro Argentino. En esta pieza interesante la acción se divide en escenas simultáneas que tienen lugar en el interior de la casa del ingeniero encargado de la construcción del puente $\mathrm{y}$ al mismo tiempo, fuera de la casa, en el puente mismo, donde juega un grupo de chicos pobres. Cae el puente en construcción y el ingeniero así como los chicos perecen en la misma sepultura. La tragedia no hace distinciones socia- 
les. El verdadero interés de la pieza estriba en las escenas simultáneas que presentan un retrato elocuente de dos ambientes -el de la clase pobre y el de los más afortunados- de la Argentina contemporánea.

Siguió a El puente otro éxito de Carlos Gorostiza, titulado $E l$ fabricante de piolín que se estrenó en la temporada de 1950. El protagonista de esta pieza es don Artemio, fabricante rico y generoso quien cae bajo la influencia de un amigo que lo explota y pervierte su carácter. Está a punto de arruinar su vida, la de su familia y de perder la fábrica cuando vuelve en sí y se deshace de la malévola influencia del supuesto amigo. Don Narciso Ibáñez Menta fué muy aplaudido por su habilidad en desarrollar la evolución psicológica de don Artemio.

Otro dramaturgo importante del teatro porteño contemporáneo es Vicente Martínez Cuitiño. Su pieza Servidumbre estrenada en el Teatro Apolo a principios del año 1950 fué muy bien recibida. Presenta a un soltero excéntrico considerado loco por sus parientes pobres y avarientos, quienes tratan de despojarlo. La pieza desarrolla la tesis de que cada ser humano tiene que servir a un ideal, a una institución o a una persona. Se le puede tachar a Cuitiño la excesiva crudeza de algunas escenas.

Los hermanos Pelayo también hacen su aporte al teatro contemporáneo. Sin embargo, su producción carece de profundidad. En El agua que se lleva el río, ${ }^{8}$ por ejemplo, se presenta a una mujer libre, cuyo amor cambia como el agua del río. Extraña el gran éxito de esta obra, de psicología tan convencional y banal.

Se está mostrando predilección por las piezas históricas y patrióticas como las de Enrique García Velloso. Su obra titulada Los amores de la virreina ${ }^{9}$ ha sido representada casi doscientas veces. La acción de esta pieza se desarrolla a fines del siglo xvirI y consiste en una serie de intrigas y enredos políticos y amorosos. Aunque la pieza tenga interés histórico, es de limitado valor artístico.

Hay que mencionar también a Enrique Suárez Deza que escribió El calendario que perdió siete días, estrenada en el Teatro Nacional Cervantes en la temporada de 1949. Se le hizo mucha propaganda a esa farsa fantástica con base en la parábola del viejo que persuade a la Muerte que cese sus actividades durante algún tiempo. Todos los elementos de la obra ya los habíamos visto en el 
Fausto de Goethe, en Don Iuan, etc. Tanto la concepción de la pieza como su representación no pasaron de mediocres.

Total: se experimenta muy poco en el teatro argentino de hoy. Se escoge lo mejor de la producción extranjera. En cuanto a la producción criolla, le faltan todavía las alas de la tradición y del vuelo libre. Sin embargo, hay talento entre los actores así como interés y entusiasmo de parte del público. Queda por ver si el extraordinario movimiento acusado entre los dramaturgos argentinos contemporáneos llevará a un nuevo florecimiento del teatro platense.

\author{
Vera F. Beck, \\ New York.
}

\title{
N O T A S
}

1 En el Teatro Nacional.

2 En el Teatro Apolo.

3 En el Gran Splendid, enero, 1950.

4 Estrenada en el Politeama Argentino, abril de 1950.

5 En el Teatro Liceo, junio de 1950.

6 Estrenada por "Los Amigos del Libro" en el Salón Kraft el 12 de noviembre de 1949 antes de llegar al escenario comercial.

7 En el Teatro Cómico, octubre, 1949.

8 Estrenada en el Gran Splendid, a fines del año 1949.

9 Estrenada en el Teatro Nacional Cervantes, marzo, 1949. 
